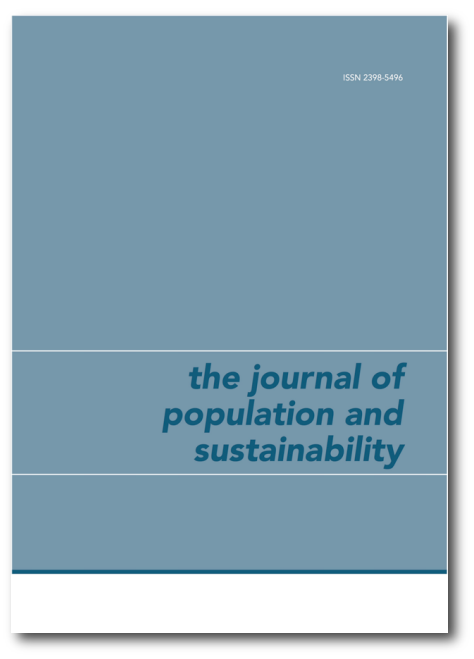

The Journal of Population and Sustainability

ISSN 2398-5496

Article title: The fractal biology of plague and the future of civilization

Author(s): William E. Rees

Vol. 5, No. 1, 2020, pp.15-30

doi: 10.3197/jps.2020.5.1.15

Open Access - CC BY 4.0 


\title{
COMMENT
}

\section{The fractal biology of plague and the future of civilization}

\author{
William E. Rees ${ }^{1}$ \\ Professor Emeritus, University of British Columbia
}

\begin{abstract}
At the time of writing, the CoViD-19 pandemic was in its second wave with infections doubling every several days to two weeks in many parts of the world. Such geometric (or exponential) expansion is the hallmark of unconstrained population growth in all species ranging from submicroscopic viral particles through bacteria to whales and humans; this suggests a kind of 'fractal geometry' in bio-reproductive patterns. In nature, population outbreaks are invariably reversed by the onset of both endogenous and exogenous negative feedback - reduced fecundity, resource shortages, spatial competition, disease, etc., serve to restore the reference population to below carrying capacity, sometimes by dramatic collapse. H. sapiens is no exception - our species is nearing the peak of a fossil-fueled 200 year plague-like population outbreak that is beginning to trigger serious manifestations of negative feedback, including climate change and CoViD-19 itself. The human population will decline dramatically; theoretically, we can choose between a chaotic collapse imposed by nature or international cooperation to plan a managed, equitable contraction of the human enterprise.
\end{abstract}

Keywords: pandemics; CoViD-19; SARS-CoV-2; fractal geometric growth; overshoot; plague; human population collapse.

1 wrees@mail.ubc.ca 


\section{Universal fundamentals of population growth}

Early in the SARS-2-CoV pandemic (Feb to Mar 2020), CoVid-19 infection rates in various European and Asian countries were doubling every two to ten days (see Nunes-Vaz, 2020). The wide spread in doubling times reflected the relative effectiveness of differing national control policies and population behaviours. Many of these nations managed to reverse the trend and 'flatten the curve', from several thousand to only a few hundred cases daily, by late May or June, a situation that obtained through the summer months. However, by early September 2020, the number of new daily CoVid-19 cases was again on the uptick. People were spending more time indoors at work, at play, at school, crowding together and more effectively transmitting the virus. Infection rates were doubling every two weeks in my home country, Canada, and doublings at an equivalent or even greater pace were again the norm in countries that had previously had things under control. The 'second wave' of the pandemic was taking serious hold and threatening to become far more serious than the first (Figure 1).

\section{Figure 1: Daily new cases of CoViD-19 in Canada}

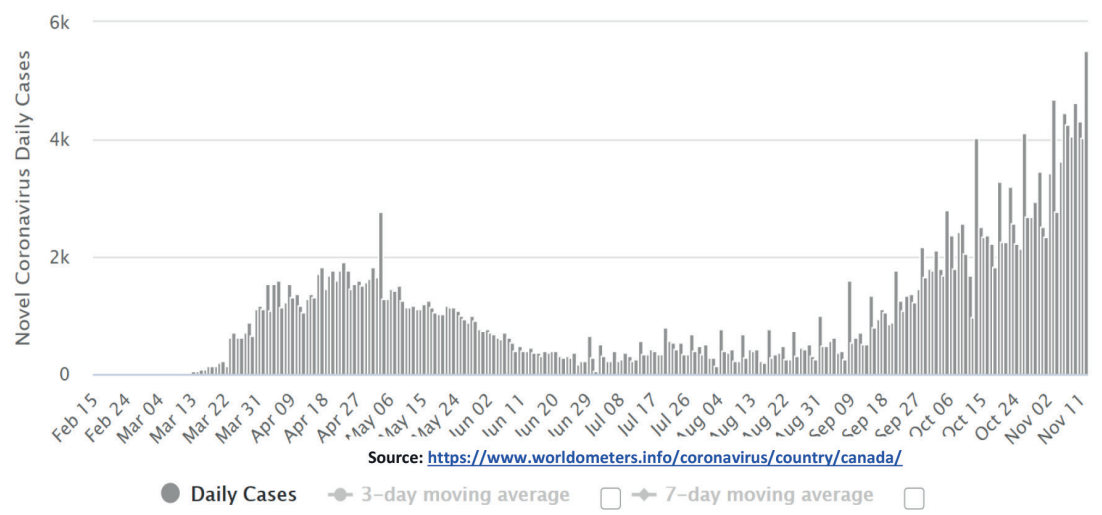


Whenever you hear reports of some entity doubling at a constant rate, think 'exponential growth' - or perhaps more accurately, geometric growth. ${ }^{2}$ Exponential/ geometric growth is the expression of natural reproductive exuberance. Virtually every living species is capable of expanding geometrically in a favourable, previously unexploited environment as SARS-2-CoV demonstrates convincingly.

Reproductive potential is perhaps the major form of positive feedback in every living system. ${ }^{3}$ Inoculate a Petri dish of nutrient-rich agar with bacteria at ideal temperature and the starter population may double in as little as 12 minutes (although some species may take a few hours). Twelve minutes later, the bacterial population will have doubled again and, after just an hour, our little colony will have expanded by a factor of 32 . So it is with all living organisms - introduced to an ideal resource-rich environment, the initial population will begin to grow geometrically. From the perspective of SARS-2-CoV, today's globally dense population of non-resistant humans is a fertile Petri dish.

What does differ among species is the generation time and hence the doubling rate. As noted, it can be just a few minutes with bacteria (or viruses); housemice have a generation time of less than ten weeks and a pair may become 40 individuals in just five months; at 7-8\%/year an unmolested population of mature blue whales or elephants can double in less than ten years; the human doubling time reached a minimum of about 33 years in the late 1960s when our growth rate maxed out at $2.1 \% /$ year.

Today's 1.05\%/year growth rate would double the current human population in 67 years (by 2087) to 15.6 billion. Fortunately, this will not happen. The rate continues its long decline; current estimates suggest that, conditions permitting, we might make 10.9 billion by the end of the century and top out shortly thereafter (Roser, 2019).

2 Some mathematicians make no distinction between 'exponential' and 'geometric' growth. Others argue that an exponential distribution involves raising each number in a series by the same power to get the next number (e.g. 2, 4, 16, 256...), while geometric growth is defined more generally as involving performing a constant operation on a sequence of numbers (e.g., 2, 4, 8, 16...).

3 'Positive feedback' implies a process that is deviation-accelerating; 'negative feedback' is deviation-correcting. 


\section{Overshoot - triggering a feedback}

In fact, conditions may not be 'permitting'. Population estimates are usually based on demographic data alone with no consideration of exogenous factors. This is unrealistic. For living organisms, the fact of their own existence ensures that no environment or habitat remains ideal for long. As the subject population expands, it will invariably use up any crucial resource in fixed supply. Even renewable resources can be depleted once the population goes into 'overshoot', a situation in which aggregate consumption exceeds food species' recovery rates or waste accumulation exceeds natural assimilative capacity. The rise and fall of reindeer populations introduced to two previously unoccupied (by reindeer) Pribilof Islands in the early $20^{\text {th }}$ Century is a classic example (Figure 2). Collapse was attributed to overgrazed food sources (primarily lichen) abetted by the stress of exceptionally cold winters (Scheffer, 1951).

Figure 2: Reindeer population outbreaks and collapse on the Pribilof Islands (Scheffer, 1951)

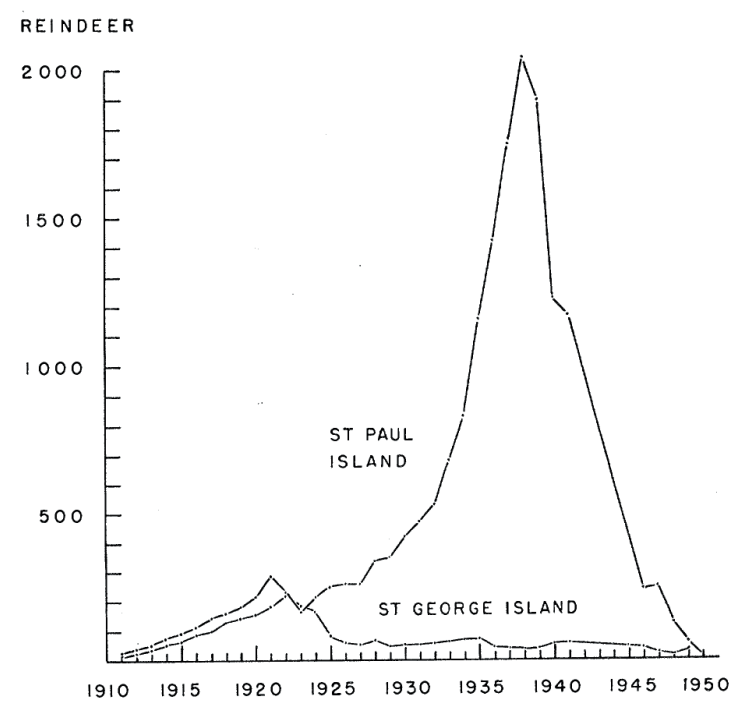

With food shortages and pollution, survival and reproductive rates necessarily decline. Meanwhile, other forms of 'negative feedback' may also set in - dense populations make our subject species more attractive to predators; crowding and malnutrition facilitate the spread of disease and parasites; there may be 
intra-specific conflict over habitat in short supply. Invariably, growth ceases and may be reversed, sometimes precipitously.

In nature, the populations of density-dependent species are determined by push and pull, the interplay of positive and negative feedback. ${ }^{4}$ Macroscopic organisms such as whales, elephants and (pre-industrial) humans typically maintain a fluctuating unstable equilibrium near their habitat's average 'carrying capacity' (though perhaps not until after a dramatic crash in the case of severe overshoot - see reindeer on St George Island, Fig 2,). Microscopic organisms have evolved quite different approaches to stress. Many species of bacteria (Bacillus, Clostridium, Desulfotomaculum, Sporosarcina, Sporolactobacillus, and Oscillospira, spp., for example) adapt to declining nutrient supply or other hostile conditions by transforming into endospores, smaller, hardy, tough-walled dormant cells that can survive conditions that would kill the active bacterium. 'Sporulation' thus protects the organism's genetic material from extreme environmental stress until the return of better times. Endospores may also be readily transported by wind or water and will reactivate within minutes or hours after being deposited in a new environment of favourable conditions.

Like the CoViD-19 virus, various small mammal and insect populations exhibit large-scale population outbreaks on an irregular basis enabled by temporarily abundant food supplies, periods of favourable weather, increased survival (e.g., from reduced predation) or some combination; other species have regular repeating high-amplitude population cycles perhaps synchronized by the seasons or, in the case of predators, by other natural cycles in prey species.

Again, like the corona virus, outbreaks of non-human animal populations can seriously harm people. The desert locust (Schistocerca gregaria), for example, may qualify as the world's most devastating agricultural pest. During the swarm phase of a locust outbreak, the insects may multiply exponentially by 20 -fold in just three months to attain densities of 80 million per square kilometre. A swarm of 80 million can consume food equivalent to the needs of 35,000 people. In 2020, favourable conditions spawned locust outbreaks - the worst in decades - in

4 Density dependent species are those subject to negative feedback triggered by their own growing populations. Negative feedback can be endogenous (e.g., reduced fecundity, infanticide) or exogenous (resource shortages, increased predation). 
several African and Asian countries including Kenya, Ethiopia, Uganda, Somalia, Eritrea, India, Pakistan, Iran, Yemen, Oman and Saudi Arabia (Njagi, 2020). Many of the affected regions are already food-stressed.

The term 'plague' is usually reserved for the horrendous zoonotic infection caused by Yersinia pestis, a bacterium usually carried and transmitted to humans by small mammals and their fleas. (The resultant 'Black Death' or bubonic plague killed 75 -200 million people in Africa and Eurasia during the 14th Century.) However, when swarms of locusts infect large geographic areas or several countries, the outbreak is also known as a plague. Even small mammal outbreaks can reach plague proportions. Australia's worst ever mouse plague caused \$A96 million of damage in 1993 (\$A184 million in 2020 dollars). The nearly equivalent 2010/11 mouse plague affected three million hectares of crops in New South Wales, as well as parts of Victoria and South Australia (CSIRO, 2020).

What all the above data illustrate is that the population dynamics of living species, from sub-macroscopic viruses to gargantuan whales, reflect a universal fractal geometry: the same basic patterns are repeated in all species, differing only in terms of vastly differing temporal and spatial scales. ${ }^{5}$

\section{Implications for humans}

How might this reality enlighten $H$. sapiens beyond helping to understand the waves of our current pandemic? To begin, humans are certainly not exempt from the fundamentals of population dynamics. For at least $99.9 \%$ of anatomically modern H.sapiens' evolutionary history (200,000 - 350,000 years) human populations, like those of other large mammals, fluctuated in the vicinity of local carrying capacities. ${ }^{6}$ Local constraints might have been relieved at times by trade

5 In theoretical mathematics, fractals are infinitely iterating, similar, detailed mathematical constructs having fractal dimensions at all scales. A fractal dimension is a ratio giving a statistical index of complexity comparing how detail in a particular fractal pattern changes with the scale of measurement. By analogy, the population dynamics of species from viruses to whales display self-similar, iterative, detailed properties (fecundity, growth rates, geometric potential, etc.) that vary among species only in terms of temporal and spatial scale.

6 Carrying capacity (CC) refers to the average maximum population of a species - the maximum fluctuates with exogenous conditions - that can be supported by a given habitat more or less indefinitely without permanent damage to that habitat. With humans, CC varies inversely with average material standard of living (consumption). 
and certainly the (possibly reluctant) adoption of agriculture $8000-10,000$ years ago enabled larger populations, permanent settlements and division of labour - and hence advanced 'civilization'. But for most of our species' time on Earth including most of the agricultural era - humanity's natural propensity to expand has been held in check by negative feedback, e.g., food and other resource shortages, disease, and inter-group conflict.

Circumstances changed with the scientific/industrial revolution, particularly the increasingly widespread use of fossil fuels. It took 200,000 - 350,000 years for human numbers to reach one billion early in the $19^{\text {th }}$ Century, but only 200 years (as little as $1 / 1750^{\text {th }}$ as much time!) to balloon another seven-fold by early in the $21^{\text {st }}$ Century. Improvements in medicine, public sanitation and population health contributed to this expansion, but coal, oil and gas made it possible. Fossil fuels are the energetic means by which humans extract, transport, and transform the prodigious quantities of food and other material resources into the products needed to support our burgeoning billions. More than any other factor, fossil fuels enabled $\mathrm{H}$. sapiens to eliminate or reduce normal negative feedbacks. Freed from historic constraints, our species was at last able to exhibit its full potential for geometric growth (Figure 3).

\section{Figure 3: Human population over the past 12,000 years (what goes up will come down)}

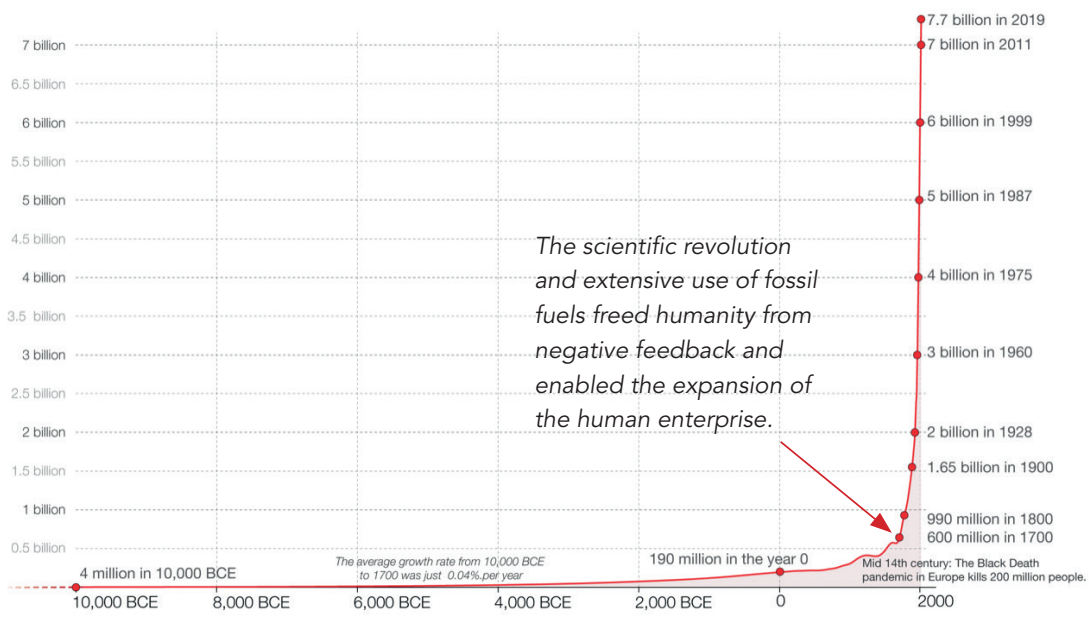


As implied above, it is not just population that has bloomed. Since 1800, propelled by a 28-fold increase in primary energy use, mostly fossil fuel, real global GDP has increased over 100 -fold. World average per capita income (consumption) is up by a factor of 13 , rising to 25 -fold in the richest countries (Roser, 2018). As Catton (1982) famously observed, Earth is being asked to accept not only more people but ever larger people.

There is hidden irony in these data. Figure 3 shows clearly that only the most recent ten or so of literally thousands of generations of humans have experienced sufficient technological change and population growth in their lifetimes to even notice it. In short, the period of spectacular growth and change people today take be the norm (and wish to preserve) represents the single most anomalous period in human evolutionary history!

Figure 3 also underscores humanity's membership in the club of fractal population dynamics. The recent accelerating surge in human numbers reflects classic geometric growth - hyper-geometric, actually, since the growth-rate increased and doubling time decreased throughout the boom period until 'peak growth' in the 1960's. At peak, humanity's numbers were doubling every 33 years. (Compare the steepening human population growth curve with the geometric phases of the CoViD-19 case count and reindeer populations in Figs 1 and 2 respectively.)

Meanwhile, Earth was not getting any bigger.

Which means, of course, that membership in the club will eventually bear a price. The so-called 'environmental crisis' has little to do with the 'environment' and everything to do with excess human demands on natural systems. For several decades, H. sapiens has been in a state of 'ecological overshoot' - our species is exploiting even renewable resources faster than species and ecosystems can regenerate and dumping (often toxic) waste at rates well beyond nature's assimilation and recycling capacities; think plunging biodiversity, collapsing fish stocks, desertification, soil depletion, tropical deforestation, ocean pollution, contamination of food supplies, rising atmospheric greenhouse gas concentrations, resultant climate change, etc., etc. By 2016, H. sapiens was 68\% in overshoot - i.e., acting as if Earth were $68 \%$ larger or more productive than it is (GFN, 2020). 
It is worth noting that, initially, most of this damage could be traced to consumption by the wealthiest $20 \%$ of humanity who have effectively appropriated $70-75 \%$ of Earth's productive and waste assimilation capacities. However, there is an upper limit to the amount any individual can consume. Today, eco-degradation is being driven primarily by rising material demands and, more importantly, by population growth in middle and low-income countries. The world community must confront egregious inequality and population growth as separate problems.

Clearly overshoot cannot be sustained indefinitely (only economists think something can grow forever). The endogenous positive feedback that dominated the geometric phase of humanity's population growth is already being countered by exogenous negative feedback including the aforementioned ecosystems degradation and the weakening of life-support functions. With overshoot, carrying capacity declines in proportion to the loss of self-producing 'natural capital' and, with it, the ability to support even existing populations. The world community is literally financing its current population and material growth by liquidating the biophysical resources and life-support functions upon which the future of the human enterprise depends; the longer we remain in overshoot, the more we compromise the ability of future generations to thrive (red curves in Figure 4).

Keep in mind, too, that degraded ecosystems are not the only source of negative feedback on human exuberance. Food and other resource scarcities will intensify geopolitical strife which, in turn, will be exacerbated by mass migrations of people abandoning areas that have become uninhabitable because of climate change or ecosystems collapse. Disease may once again emerge as a major scourge - crowded human populations weakened by hunger and stress, no longer protected by functional public health systems, present ideal conditions for the spread of resurgent pathogens.

Or new ones. Approximately $70 \%$ of the new diseases in humans in recent decades, including CoViD-19, are zoonoses, ailments caused by pathogens transmitted from animals (the SARS-2-CoV virus jumped to people from bats or pangolins). CoViD-19, itself an exemplar of negative feedback, is at least the sixth global health pandemic since the Great Influenza of 1918 - and it may be a harbinger of worse to come. A recent report notes that there are six to eight hundred thousand 
unknown viruses in nature that could infect people as humans encroach ever more insistently on wildlife habitats. "Future pandemics will emerge more often, spread more rapidly, do more damage to the world economy and kill more people than CoViD-19 unless there is a transformative change in the global approach to dealing with infectious diseases..." (IPBES, 2020). Pandemics may originate from contact with animals, but their emergence is driven by human activities.

And what about our energy conundrum? Modern society is precariously suspended on a gusher of fossil fuel - despite significant advances in socalled renewable energy for electricity generation ${ }^{7}$ coal, oil and natural gas still provided 84\% (492.3 exajoules) of the world's primary energy in 2019 (BP 2020). The problem is that, to avoid potentially catastrophic climate change, the global economy must decarbonize by 2050. In the absence of quantitatively similar renewable substitutes, this implies significant energy (and food and other resource) shortages, shrinking GDP and a major reset of societal priorities.

Even the option of risking climate change by continued reliance on fossil fuel may be closing. Economically viable sources of oil and gas require ever greater levels of investment just to maintain supplies. Ironically, the onslaught of CoViD-19 has so deflated demand for oil and gas that the resultant glut has destroyed investment. Meanwhile, production has fallen precipitously, and low prices have bankrupted dozens of companies. Some wonder whether the industry can recover (e.g., Cho 2020) but the problem is much greater. Society as we know it cannot survive the absence of abundant cheap energy.

\section{Where do we go from here?}

A bacterial culture can quickly overwhelm and deplete its Petri dish; the SARS2-CoV virus will continue to ravage the human population until herd immunity or a successful vaccine cuts it off. This is the way of living things, including humans - our species has expanded over the entire planet and is well on the way to depleting resources essential to its own survival. Earth is to $H$. sapiens as Petri dish is to Bacillus sp.

7 Wind turbines and solar PV panels are not truly renewable, merely replaceable, and their production involves mining, refining and manufacturing processes dependent on fossil fuel. Indeed, many key direct uses of fossil fuels - high-heat manufacturing, inter-urban, air and marine transportation, agriculture - are not readily electrifiable. 
The analogy, or rather 'homology', goes quirkily further. When the bacterium's medium turns hostile, its cells sporulate; the resultant endospores wait in dormant state to be wafted to a more favourable environment. How does this adaptation differ functionally from NASA's inquiries into using suspended animation to facilitate human interstellar travel (Bagelley, 2017) or plans to colonize Mars to ensure that humans survive a war-ravaged or eco-degraded Earth (Solon 2018; McFall-Johnsen and Mosher 2020)?

Whether H.sapiens will ever reach some Earth-like planet ' $x$ ' light-years away or even successfully colonize Mars, may be entirely moot. In the best of circumstances, serious interplanetary exploration, even within the solar system, would be decades in the future and these are hardly the best of circumstances. The 'Anthropocene' is quickly becoming dominated by negative feedback induced by the already excessive scale of the human enterprise.

Not that this makes much difference to decision-makers. Despite cumulative evidence of potential disaster, the world's major governments, international development organizations, the corporate sector and probably the majority of even well-educated citizens are fully committed to maintaining the global cultural narrative of perpetual economic growth abetted by continuous technological progress. It seems that few people comprehend the physical implications of humanity's material addiction. When something is growing geometrically (e.g., plague-like) with a constant doubling period, the quantity attained at the end of any doubling period is greater than the sum of the quantities at the end of all previous doublings (e.g., $\left.128>\sum(64+32+16+8+4+2+1)\right) .^{8}$ More or less on geometric projection, the global material footprint rose from 43 billion tonnes/year in 1990 to 92 billion in 2017 - an increase 113\%. Similarly, half the fossil fuels ever used were burned in just the past 30 years ( $90 \%$ has been consumed since 1943). Consider, then, that with population growing at 1.0\%/year and incomes in developing countries increasing even faster, the global economy will more than double again the next 30 years (i.e., $>2.0 \%$ /year). Since much of that income growth will be in countries where people have yet to satisfy basic needs let alone luxury wants, we can expect parallel growth in economic energy and material throughput - the material footprint is projected to expand another 106\% to 190 tonnes/year by 2060 (UN 2019).

8 Alternatively, with geometric growth, the quantity consumed during the latest doubling period is greater than the sum of quantities consumed in all previous doubling periods. 
All this on a planet already $68 \%$ in overshoot; unable to control soil and landscape degradation; beginning to reel from climate change; witnessing a 68\% drop in the populations of hundreds of regularly monitored vertebrate species world-wide since 1970; etc., etc. What is the likely impact of imposing an energy, material, and waste load on the ecosphere in just the next 30 years potentially greater than the sum of the loads imposed by all previous doublings since the beginning of the $19^{\text {th }}$ Century?

The time has come to face biophysical reality. Contemporary data and trends suggest that global society is nearing the end of an unprecedented - and likely one-off - human population outbreak (Fig 1) affecting the entire planet. ${ }^{9}$ Distasteful as it may seem to human exceptionalists, we can justifiably describe $H$. sapiens seeming dominance as a form of global plague, a description that would surely apply if we were discussing any other species (Rees, 2020).

On our present course, the likely outcome for global society is systems collapse as we run up against serious climate effects, resource shortages, and increasing geopolitical conflict in coming decades. Compare the 'overshoot' simulation in Figure 4 (red curves) with the real-world boom-bust collapse of the St Paul Island reindeer herd as it depleted its food resources (Fig. 2).

Forget about interstellar space travel or even colonizing dead-cold Mars. Humans should be focused on regenerating ecosystems and life-support functions on Earth, the planet on which we evolved, which continues to sustain us and for which we are best adapted. Despite damage wrought by $H$. sapiens, Earth remains infinitely more hospitable than the red planet; why would anyone think that efforts to terraform Mars is more likely to pay off than restoring the earth?

\section{Epilogue - the choice before us}

CoViD-19 may well exemplify the biological universal to expand that H.sapiens shares with all other life-forms. But humans have other unique qualities that we have yet to exercise fully in addressing overshoot. Our species is blessed with high intelligence, the capacity to reason logically from the evidence, and the ability to plan ahead in ways that could dramatically alter our future prospects.

9 "One off" because, with all readily accessible resources used up, survivors would likely be unable to resurrect a technologically advanced global civilization. 
Figure 4: Alternative pathways - overshoot-to-collapse (red lines) or controlled contraction to 'one-planet living' well within Earth's human carrying capacity (green line)

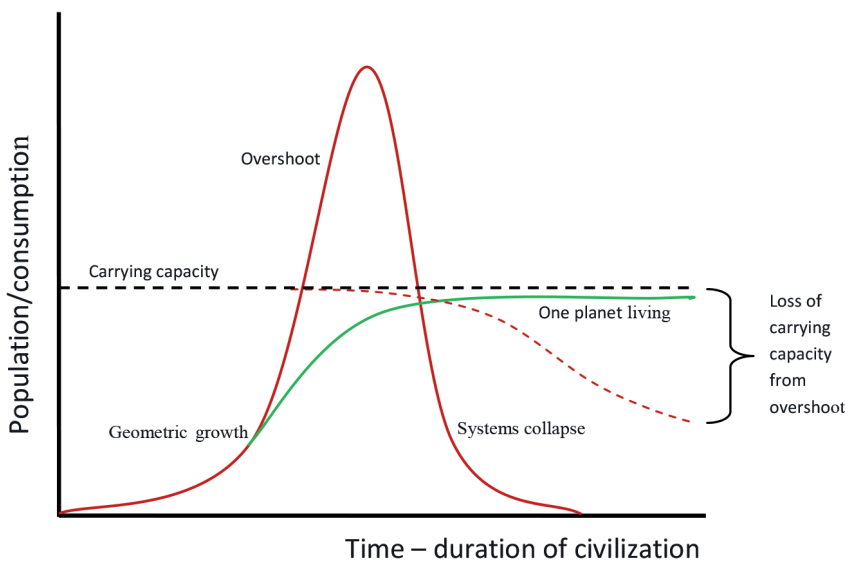

It helps that we also possess a unique appreciation of our own vulnerability and mortality, no doubt heightened by the current pandemic.

The scientific evidence tells us that some form of contraction of the human enterprise is a material necessity if we to maintain the functional integrity of the ecosphere. It seems we have a choice: either allow nature to take its course and suffer the ugly consequences of a chaotic implosion or rise to our true potential by executing a controlled down-sizing of the human enterprise. The overall goal must be 'one-planet living' which means learning to thrive more equitably on Earth well within the carrying capacity of the ecosphere (Moore and Rees, 2013). When dealing with the human plague, this is the real meaning of 'flattening the curve' (Fig. 4).

The question is: how can the self-proclaimed most-intelligent-species-on-Earth organize socially, politically, and economically to implement a process to ensure an orderly and equitable contraction? Could there be a more riveting intellectual and practical challenge? Indeed, this, more than fear, is proving to be the real motivation for some of our best minds in dealing with our (un)sustainability crisis (see, for example the degrowth initiative at https://www.degrowth.info/en/ what-is-degrowth/). If the global community does not rise fully to engage 
its fate, humanity proclaims itself to have no more practical intelligence or conscious moral agency when it comes to ensuring its own survival than does the CoViD-19 virus.

\section{References}

Baggaley, K., 2017. Cryosleep may open the door to deep space: here's how. Mach, NBC News [online] 12 June. Available at: https://www.nbcnews.com/ mach/tech/cryosleep-may-be-key-deep-space-missions-here-s-how-ncna770961 [Accessed 12 November 2020].

BP, 2020. Statistical review of world energy 2020. [pdf] London: British Petroleum. Available at: https://www.bp.com/content/dam/bp/business-sites/en/global/ corporate/pdfs/energy-economics/statistical-review/bp-stats-review-2020-fullreport.pdf [Accessed 10 November 2020].

Catton, W.R., 1982. Overshoot - the ecological basis of revolutionary change. Urbana: University of Illinois Press.

Cho, R., 2020. Will the pandemic spell the end for oil and gas? State of the Planet, Earth Institute Columbia University [blog] 24 September. Available at: https:// blogs.ei.columbia.edu/2020/09/24/pandemic-fatal-blow-oil-gas/ [Accessed 10 November 2020].

CSIRO, 2020. Tracking Australia's mice - case study. [online] Canberra: Commonwealth Scientific and Industrial Research Organization. Available at: https://www.csiro.au/en/Research/Farming-food/Invasive-pests/Mouse-Census [Accessed 5 November 2020].

GFN, 2020. Country trends (world). [online] Global Footprint Network. Available at: https://data.footprintnetwork.org/?_ga=2.210507157.1419130515.16052258961508465399.1522539523\#/countryTrends? cn=5001\&type=BCtot, EFCtot [Accessed 9 November 2020].

IPBES, 2020. IPBES media release: pandemics report: escaping the 'era of pandemics'. [online] Bonn: Intergovernmental Science-Policy Platform on Biodiversity and Ecosystem Services. Available at: https://ipbes.net/pandemics [Accessed 7 November 2020].

McFall-Johnsen, M. and Mosher, D., 2020. Elon Musk says he plans to send 1 million people to Mars by 2050 by launching 3 Starship rockets every day and 
creating 'a lot of jobs' on the red planet. Business Insider. [online] Available at: https://www.businessinsider.com/elon-musk-plans-1-million-people-to-marsby-2050-2020-1 [Accessed 12 November 2020].

Moore, J. and Rees, W.E., 2013. Getting to one planet living. In: L. Starke, ed. 2013. State of the world 2013 - is sustainability still possible? Washington: Island Press. pp.39-50.

Njagi, D., 2020. The biblical locust plagues of 2020. BBC Future Planet Africa. [online] Available at: https://www.bbc.com/future/article/20200806-thebiblical-east-african-locust-plagues-of-2020\#: :text=Desert\%20locusts\%2C\%20 or\%20Schistocerca\%20gregaria, increase $\% 20$ and $\% 20$ they $\% 20$ become $\% 20$ crowded.\&text $=$ When\%20swarms\%20affect\%20several\%20countries, is $\% 20$ known\%20as\%20a\%20plague [Accessed 9 November 2020].

Nunes-Vaz, R., 2020. Visualising the doubling time of COVID-19 allows comparison of the success of containment measures. Global Biosecurity, 1(3). [online] Available at: https://www.jglobalbiosecurity.com/articles/10.31646/gbio.61/ [Accessed 16 November 2020].

Rees, W.E., 2020. Ecological economics for humanity's plague phase. Ecological Economics, 169(106519). https://doi.org/10.1016/j.ecolecon.2019.106519

Roser, M., 2018. Economic Growth. [online] Available at: https://ourworldindata. org/economic-growth [Accessed 10 November 2020].

Roser, M., 2019. Future population growth. [online] Available at: https:// ourworldindata.org/future-population-growth\#global-population-growth [Accessed 6 November 2020].

Scheffer, V.B., 1951. The rise and fall of a reindeer herd. Scientific Monthly, 73(6) pp.356-362.

Solon, O., 2018. Elon Musk: we must colonise Mars to preserve our species in a third world war. The Guardian [online] 11 March. Available at: https://www. theguardian.com/technology/2018/mar/11/elon-musk-colonise-mars-thirdworld-war [Accessed12 November 2020].

UN,2019.12-Responsibleproductionand consumption. [online]Availableat:https:// unstats.un.org/sdgs/report/2019/goal-12/\#: :text=\%E2\%80\%9CMaterial\%20 footprint\%E2\% $80 \% 9$ D\%20refers\%20to\%20the,to\%20meet $\% 20$ final $\% 20$ 
consumption \%20demands. \&text=The\%20global\%20material\%20footprint\%20 rose,113\%20per\%20cent\%20since\%201990 [Accessed 12 November 2020].

Woolaston, K. and Fisher, J. L., 2020. UN report says up to 850,000 animal viruses could be caught by humans, unless we protect nature. The Conversation. [online] Available at: https://theconversation.com/un-report-says-up-to-850-000-animalviruses-could-be-caught-by-humans-unless-we-protect-nature-148911 [Accessed 7 November 2020]. 